\title{
Association between ACTN3 and acute mountain sickness
}

Ricardo Muller Bottura ${ }^{1 *}$ (D), Giscard Humberto Oliveira Lima ${ }^{2}$, Debora Cristina Hipolide ${ }^{1}$ and João Bosco Pesquero ${ }^{2}$

\begin{abstract}
Background: During the process of acclimatization, when our organism needs to adjust several metabolic processes in the attempt of establishing a better oxygenation, it is normal that individuals present some symptoms that can lead to the disease of the mountain. However, not everyone presents such symptoms and individuals native of high altitudes regions present genetic differences compared to natives of low altitudes which can generate a better acute adaptation. One of these differences is the higher proportion of type I muscle fibers, which may originate from the R577X polymorphism of the ACTN3 gene. The aim of this study was to compare the response of individuals with different ACTN3 genotypes at simulated $4500 \mathrm{~m}$ altitude on the presence of Acute Mountain Sickness (AMS) symptoms. Twenty-three volunteers ( $R R=7, R X=8, X X=8$ ) spent 4 hours exposed to a simulated altitude of $4500 \mathrm{~m}$ inside a normobaric hypoxia chamber. Lactate and glucose concentrations, $\mathrm{SpO}_{2}$, heart rate and the symptoms of AMS were analyzed immediately before entering the chamber and at each hour of exposure. Statistical analysis was performed using IBM SPSS Statistics 21 software.
\end{abstract}

Results: Our results point to an association between AMS symptoms and the presence of $\mathrm{R}$ allele from R577X polymorphism.

Conclusion: We conclude that individuals with at least one R allele of the R577X polymorphism seems to be more susceptible to the effects of hypoxia during the acclimatization process and may develop AMS symptoms.

Keywords: ACTN3, Acute Mountain sickness, Acclimatization, Altitude, Hypoxia, Hypoxemia, Muscle Fiber types

\section{Introduction}

While we ascend high altitudes, the pressure of oxygen present in the air descends. This phenomenon is known as hypobaric hypoxia and results in decreased pressure of oxygen in arterial blood, which is called hypoxemia [1]. An environment of hypobaric hypoxia, as found at high altitudes, affects several body systems even if exposure to this environment is acute (7 days) [2,3]. The simple fact of ascending and exposing itself to a certain altitude causes our body to promptly initiate a series of adaptations to compensate for the decrease in the supply of oxygen $[1,4,5]$, such as increased heart rate [6], use of glucose as substrate $[7,8]$ and consequent increase in lactate [9]. At $4500 \mathrm{~m}$, the real amount of oxygen in the air composition is only $12 \%$ diluted, which is approximately $60 \%$ of sea level oxygen [10]. This lower oxygen

\footnotetext{
* Correspondence: rbottura@hotmail.com

${ }^{1}$ Department of Psychobiology, UNIFESP, Botucatu Street, 862, First Floor, Vila

Clementino, SP, ZIP, São Paulo 04023062, Brazil

Full list of author information is available at the end of the article
}

pressure causes arterial desaturation (hypoxemia) that is perceived by peripheral chemoreceptors [11] causing increased ventilation and increased sympathetic activation [12], raising heart rate and cardiac output [13]. There are many people who seek high altitudes, whether for work, as miners in Chile and Peru that reach $4500 \mathrm{~m}$ [14] or only for sport or entertainment [15]. This high frequency of people at high altitudes between $4500 \mathrm{~m}$ and $5000 \mathrm{~m}$ brings concern, since $50 \%$ of them end up suffering from AMS symptoms [16], which involves headache, fatigue, dizziness, anorexia and nausea. Headache is the most frequent symptom [17], caused mainly by the decrease in arterial oxygen saturation [18-20]. The AMS diagnosis is made by a self-assessment questionnaire called the Lake Louise Score [21]. For the diagnosis it is necessary that the individual is above $2500 \mathrm{~m}$ and has the presence of at least two symptoms, one of them being headache [17]. The factors that predispose individuals to AMS symptoms are focus of several studies, including the search for some genetic relation, but without any conclusive results [22] 
There are still many questions to be answered about the effects of different altitudes in the acclimatization process, but the literature helps to understand the chronic effects of hypoxemia, especially when analyzing populations living in high altitude regions. The Sherpas, Tibetans [23] and Quechuas [24] have a higher proportion of type I muscle fibers than individuals born in lower regions. These fibers have a higher mitochondrial density than type II fibers and this relationship between the distribution of muscle fiber types and populations born at high altitudes presupposes a genetic predisposition. In addition to the mitochondrial density difference between muscle fiber types, there is a structural difference in the sarcomere of these fibers. The actin filament binds to the Z-line by a protein that is found in two forms in skeletal muscle: $\alpha$-actinin (ACTN2 and ACTN3), ACTN2 being present in all fiber types, whereas ACTN3 is present only in type II fibers, especially type IIx fibers $[25,26]$. However, the ACTN3 gene undergoes a mutation that results in the exchange of an arginine by a stop codon at position 577 of the protein causing some individuals not to express ACTN3, which is a hereditary deficiency [25]. However, little is known about the effects of acute exposure to hypoxia in relation to genetic differences and therefore it is necessary to investigate in more detail how different genotypes can influence the acclimatization process. Therefore, the aim of this study was to verify the influence of the R577X polymorphism of the ACTN3 gene on the symptoms of the AMS during the process of acclimatization in healthy individuals exposed 4 hours to simulated high altitude (4500 m).

\section{Materials and methods Participants}

This study was carried out in two stages, the first of which was the collection of epithelial cells from the buccal mucosa from 61 volunteers ( 39 men and 22 women) for the genetic evaluation of the ACTN3 R577X polymorphism, with twenty-one RR (34.4\%), thirty-two RX (52.5\%) and eight XX (13.1\%). In addition, volunteers responded to the International Physical Activity Questionnaire (IPAQ). The second stage was carried out in the premises of Clube Escola of Universidade Federal de São Paulo (UNIFESP). To participate in the study, volunteers had to be physically active, according to the IPAQ and between 17 and 45 years of age and have no history of cardiovascular diseases. Volunteers who were exposed to altitudes above $2500 \mathrm{~m}$ up to 6 months prior to the experiment were excluded from the study. The $A C T N 3$ distribution of volunteers participating to the second stage was $\mathrm{RR}=7, \mathrm{RX}=8$ and $\mathrm{XX}=8$.

\section{Experimental design}

After the first stage of the experiment, individuals returned to the laboratory for the experimental procedure inside the normobaric chamber to $4500 \mathrm{~m}$ of altitude. In this situation, volunteers were evaluated in five different moments: (1) immediately before entering the chamber, (2) 1 hour of exposure to hypoxia, (3) 2 hours of exposure to hypoxia, (4) 3 hours of exposure to hypoxia and (5) 4 hours exposure to hypoxia. Blood samples were collected at each time point for evaluation of plasma lactate and glucose concentrations; heart rate (HR) and peripheral oxygen saturation $\left(\mathrm{SpO}_{2}\right)$ were measured at each moment (Fig. 1). All volunteers were evaluated in the morning and received a standard snack after the first analysis before entering the chamber.

\section{DNA EXTRATION}

To determine the genotype of the ACTN3 R557X gene, epithelial cells from the buccal mucosa were collected using a swab on the inside of the cheek, for approximately $30 \mathrm{~s}$. The samples were then stored in a cooled thermal box to preserve the material at low temperature $\left(4{ }^{\circ} \mathrm{C}\right)$ until it was transported to the laboratory. This collection method was chosen because it is a quick, lowinvasive, painless, low-cost procedure and still provides a quality genomic DNA sample. Genomic DNA was extracted using the Chelex 100 resin following the manufacturer's recommended protocol [27].

\section{DNA quantification}

The quantification of the genomic DNA was performed in a NanoDrop-ND1000 spectrophotometer. This equipment evaluates the amount of DNA, uses small volumes $(1 \mu \mathrm{L})$ without the need of dilution and provides parameters to evaluate its purity, regarding the presence of proteins and phenolic compounds [28].

\section{qPCR GENOTYPING}

The SNP (single nucleotide polymorphism) analyzes of the ACTN3 gene were made by the qPCR allele discrimination method (quantitative PCR) using the TaqMan ${ }^{\circ}$ SNP genotyping assays (Applied Biosystems, Foster City, CA) and QuantStudio 5 (Applied Biosystems ${ }^{\oplus}$ ). The technique allows the analysis of the two variant alleles of a SNP in a particular segment of DNA. For this experimental approach, $\mathrm{TaqMan}^{\circ}$ assays that have already been functionally tested (ACTN3 rs1815729) were used, because they offer better performance and more affordable cost compared to the customization of the tests [29].

\section{NORMOBARIC altitude chamber}

The Altitude Simulator (CAT - Colorado Altitude Training $^{\mathrm{Tm}} / 12$ CAT-Air Unit) simulates up to $4500 \mathrm{~m}$. This equipment has two air units installed outside the chamber, which performs the gas exchange, increasing nitrogen and reducing $\mathrm{O}_{2}$. This gas exchange generates difference in the $\mathrm{O}_{2}$ concentration inside the chamber 


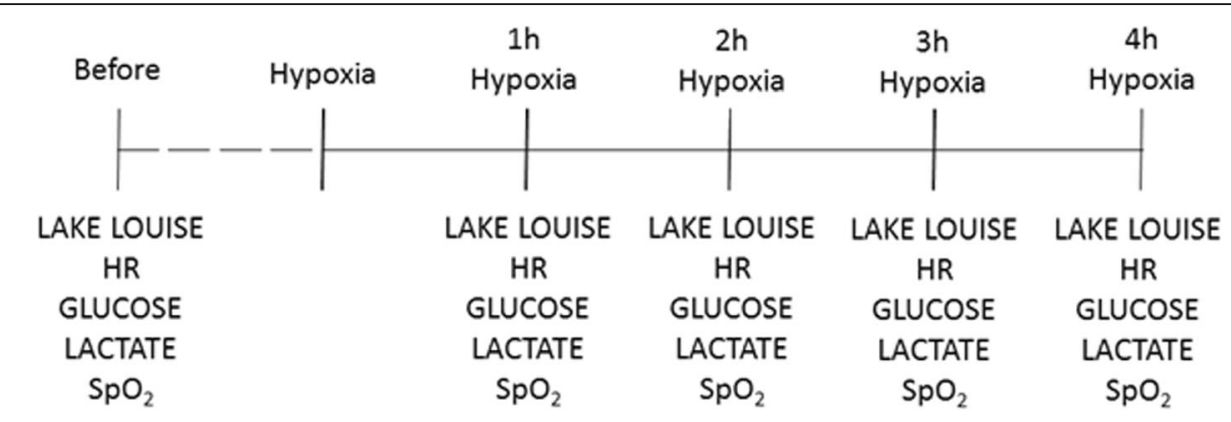

Fig. 1 Experimental Design. Participants were evaluated at five different times, the first before entering the camera. Heart Rate (HR), glucose, lactate and peripheral oxygen saturation $\left(\mathrm{SpO}_{2}\right)$ were measured at each moment. Participants presented for the procedure in groups of three, four or five people at a time, randomly among the genotypes

that is visible in a display that shows the simulated altitude in real time, measured by a module that contains an $\mathrm{O}_{2}$ cell sensitive to its variations.

\section{AMS symptoms}

In order to diagnose AMS, we used a self-assessment questionnaire called the Lake Louise Score [21, 30], which consists in punctuating from zero to three $(0=a b-$ sence, $1=$ mild, $2=$ moderate; $3=$ severe) the presence of four symptoms (headache, nausea or lack of appetite, fatigue or weakness, dizziness). For the diagnosis it is necessary that the individual is above $2500 \mathrm{~m}$ and has the presence of at least two symptoms (totalizing at least 3 points), one being a headache (with at least 1 point) $[17,30]$.

\section{Physiological variables}

Peripheral oxygen saturation $\left(\mathrm{SpO}_{2}\right)$ was monitored using a Fingerpulse ${ }^{\circ}$ finger oximeter, model MD300C202, using a dual light source (a red LED and a red infrared LED) and a photodetector that detects variations in light absorption in the arterial blood, since other tissues such as bones and venous vessels normally absorb a constant amount of light over time. The wavelength of the LED is $660 \mathrm{~nm}$ and the infrared LED is $905 / 880 \mathrm{~nm}$ with a maximum optical output power of $4 \mathrm{~mW}$. Heart rate (HR) was measured using the same Fingerpulse ${ }^{\circ}$ finger oximeter model MD300C202 since the use of this type of appliance at rest is adequate [31]. The glucose and lactate evaluations were performed through blood sample collected from the tips of the fingers. At each collection the fingertips were sanitized with BIOSOMA alcohol swab and later drilled with a BIOLAND Model SB-323 auto lancet. The quantification of these variables was performed through reflectance photometry through ROCHE's Accutrend Plus Monitor, a portable analyzer for the quantitative determination of glucose, lactate, cholesterol and triglycerides [32].

\section{Statistics analysis}

To analyze the association between the physiological variables and our study variable (presence of AMS symptoms), we used a Generalized Estimating Equations (GEE) with Tweedie distribution, in which the values of each time were condensed into a single variable counting 114 values (23 individuals, 5 times, less 1 lactate time which an error occur with the equipment). Tweedie distribution was used to fit our GEE model using the results of Lake Louise Score as our main variable in which the most of responses was zero, since Tweedie distribution fit both discrete and continuous data [33, 34]. The GEE model with Tweedie distribution was used to investigate if a physiological variable or ACTN3 polymorphism was associated with an increased chance to develop AMS. In the GEE with the presence of ACTN3 genotypes and with glucose $3 \mathrm{~h}$ and glucose $4 \mathrm{~h}$ as covariates, the latter entered only the values of these moments. The level of significance was $\alpha \leq 5 \%$. To perform the tests, the IBM SPSS Statistics 21 software was used.

\section{Results}

\section{Acute mountain sickness}

During the $4 \mathrm{~h}$ of exposure to low oxygen pressure mimicking high altitude, three volunteers presented scores related to AMS. One of these volunteers (RX; IMC = $24.7 \mathrm{~kg} / \mathrm{m} 2$ ) presented a score 4 between the moments of 2 to $3 \mathrm{~h}$, however, without presence of headache, which eliminates the diagnosis. Of the other two volunteers who presented symptoms (both RRs), one of them $(\mathrm{BMI}=24.8 \mathrm{~kg} / \mathrm{m} 2)$ had score 4 at the moment $3 \mathrm{~h}$ and score 6 at the moment $4 \mathrm{~h}$, while the other volunteer $(B M I=21.7 \mathrm{~kg} / \mathrm{m} 2)$ presented score 4 at the moment $4 \mathrm{~h}$. In both cases, one of the symptoms reported was headache, which validates the diagnosis of AMS. There were no differences between them and the other volunteers of this study for age, weight, height or BMI (Table 1).

In order to verify which physiological variables could explain the presence of AMS symptoms, we performed a GEE in which we used the HR, glucose, lactate and $\mathrm{SpO}_{2}$ variables analyzed during the whole time of exposure to hypoxia $(N=114)$ and we found only $\mathrm{SpO}_{2}$ association $\left[\mathrm{X}^{2} \quad(1, \quad \mathrm{~N}=114)=3.58, p=0.05\right]$ with the 
Table 1 Characteristics of AMS and no-AMS groups

\begin{tabular}{lll}
\hline & AMS $(n=2)$ & No-AMS $(n=21)$ \\
\hline Age (years) & $29.50 \pm 0.71$ & $28.81 \pm 8.60$ \\
Weight $(\mathrm{kg})$ & $67.00 \pm 14.14$ & $70.52 \pm 15.30$ \\
Height $(\mathrm{m})$ & $1.69 \pm 0.09$ & $1.68 \pm 0.09$ \\
BMI $\left(\mathrm{kg} / \mathrm{m}^{2}\right)$ & $23.29 \pm 2.22$ & $24.78 \pm 3.49$ \\
\hline
\end{tabular}

Note: characteristics of groups represented by mean \pm SD with no statistical differences

symptoms reported through the Lake Louise questionnaire. This result indicates that there is an inverse relationship between the variables, meaning that the lower the value of $\mathrm{SpO}_{2}$, the higher the probability of the volunteer to report a symptom in the questionnaire $(\beta=-$ $0.04,95 \% \mathrm{CI}=-0.09 /-0, P=0.05)$. Figure 2 shows the relationship between the physiological variables and scores of Lake Louise during all exposure time to hypoxia.

\section{ACTN3 R577X and AMS}

To test our hypothesis of the acclimatization difference of the R577X polymorphism of the ACTN3 gene, we included in the statistical model the ACTN3 and the glucose data after 3 and $4 \mathrm{~h}$ of exposure, since it was in these moments that volunteers presented the symptoms of AMS $(N=114)$. The results are shown in Table 2 .

The statistical model showed association of AMS symptoms with $\mathrm{SpO}_{2}\left[\mathrm{X}^{2}(1, N=114)=5.56, p=0.01\right]$ and ACTN3 $\left[\mathrm{X}^{2}(1, \mathrm{~N}=114)=15.60, p<0.01\right]$. Considering ACTN3 genotypes, $\mathrm{RX}(\beta=1.78,95 \% \mathrm{CI}=0.62$ /
2.95, $p<0.01)$ and $\mathrm{RR}(\beta=2.08,95 \% \mathrm{CI}=1.02 / 3.13, p<$ $0.01)$ are associated with Lake Louise, when controlled by the glucose levels after 3 and $4 \mathrm{~h}$. The data expressing these associations are shown in Table 3.

\section{Oxygen saturation}

In order to investigate which physiological variables could explain the decrease in $\mathrm{SpO}_{2}$ over time, we correlated $\mathrm{HR}$, lactate and glucose to verify their behavior against $\mathrm{SpO}_{2}$ but did not find any variable that showed significant values.

\section{Discussion}

Several studies have demonstrated the influence of low oxygen pressure at high altitude with AMS, however, in our study we expected that no volunteer would develop AMS. The reason for this assumption is that we have controlled most of the risk factors such as obesity [35], physical effort [36] and low glycemia [37], since our volunteers had a meal just before entering the chamber, did not have any physical activity inside and had normal BMI. Furthermore, our volunteers were exposed only for 4 hours at conditions mimicking $4500 \mathrm{~m}$. Even having controlled all those risk factors, almost $10 \%$ of our volunteers had AMS. First we evaluated whether AMS was related to a decreased $\mathrm{SpO}_{2}$ since it is the main inducing factor. Interestingly we could demonstrate in our study an association between $\mathrm{SpO}_{2}$ with AMS symptoms which corroborates a three-month study in 506 mountaineers of different nationalities in the Alps between $2200 \mathrm{~m}$ and $3817 \mathrm{~m}$, that applied the Lake Louise

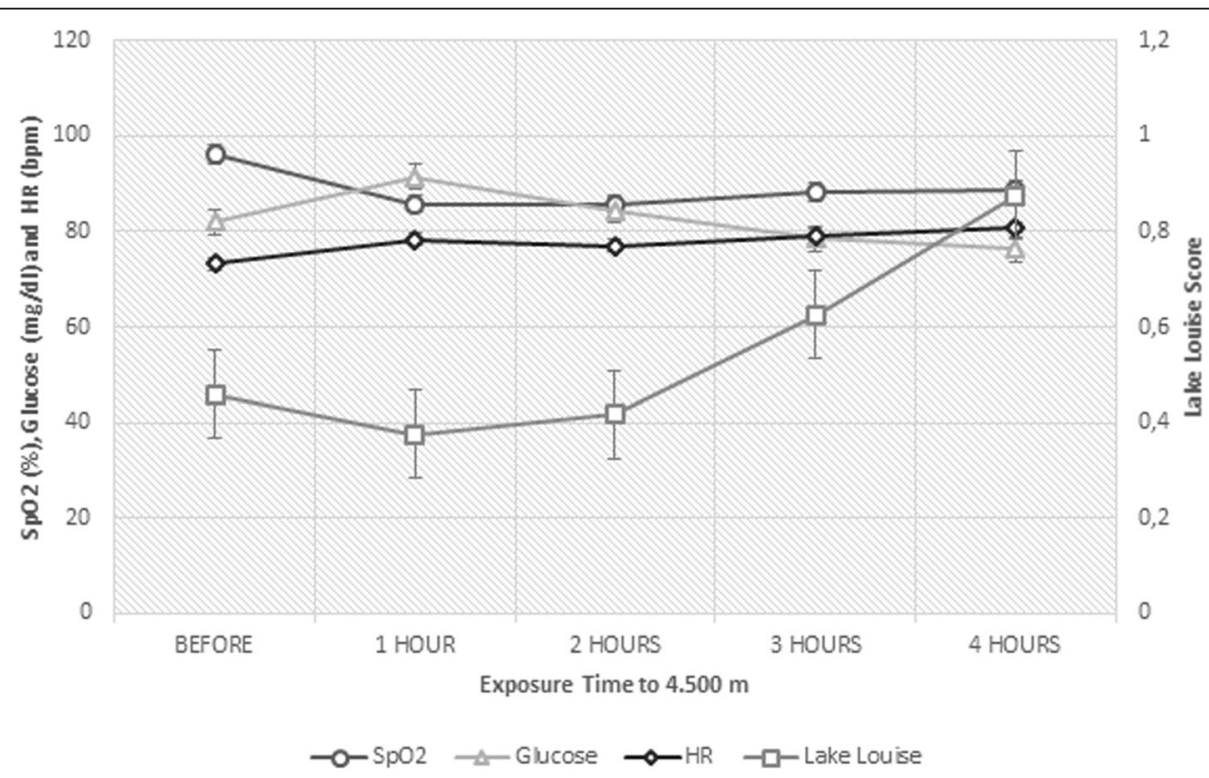

Fig. 2 Physiological Variables in relation to Lake Louise scores during 4 hours exposure to hypoxia. Relationship between the physiological variables SpO2, glucose and HR with mean Lake Louise scores during the five moments of evaluation. The variable lactate did not enter the graph because it did not show relation to the score or change over time. Values represent the mean of $\mathrm{ALL}$ volunteers ( $n=23$ ) at each time 
Table 2 Result of GEE analysis for Lake Louise, $\mathrm{SpO}_{2}, \mathrm{ACTN} 3$ and glucose in the moments of 3 and $4 \mathrm{~h}$

\begin{tabular}{llll}
\hline Variable & \multicolumn{2}{l}{ Hypothesis Test } & \\
\cline { 2 - 4 } & $x^{2}$ & Df & $P$ \\
\hline $\mathrm{HR}$ & 0.220 & 1.0 & 0.63 \\
$\mathrm{SpO}_{2}$ & 5.560 & 1.0 & $0.01^{*}$ \\
Lactate & 0.530 & 1.0 & 0.46 \\
ACTN3 & 15.604 & 1.0 & $<0.01^{*}$ \\
glucose 3 h & 0.002 & 1.0 & 0.96 \\
glucose 4h & 2.938 & 1.0 & 0.08 \\
\hline
\end{tabular}

Note: The association between the physiological variables, the ACTN3 and Lake Louise scores was verified through a GEE analysis including all values of each volunteer in the five times (before, $1 \mathrm{~h}, 2 \mathrm{~h}, 3 \mathrm{~h}$ and $4 \mathrm{~h}$ ), totaling 114 values for each variable. The following variables were included in the statistical model: Heart Rate (HR), Peripheral Oxygen Saturation $\left(\mathrm{SpO}_{2}\right), A C T N 3$, lactate, glucose 3 Hours and glucose 4 Hours

*Association with increased symptoms of Lake Louise

questionnaire and measured $\mathrm{SaO}_{2}$ and $\mathrm{HR}$ and demonstrated that the main symptom of AMS, headache, is directly related to low $\mathrm{SaO}_{2}$, in addition to high perception of effort and low water consumption [18]. Our results reinforce this interaction, since among all the physiological variables analyzed only $\mathrm{SpO}_{2}$ was associated with the symptoms reported by the volunteers.

We also analyzed the probability of $A C T N 3$ being a risk factor to AMS, since both of our volunteers that developed the symptoms had the same genotype (RR). Therefore, the association between the ACTN3 R577X polymorphism with the presence of AMS symptoms is the main result of our study. Although several genes have been studied in an attempt to find a relationship with the symptoms $[22,38,39]$, our study is the first to correlate this condition to ACTN3 R577X genotypes, showing that individuals with at least one $\mathrm{R}$ allele are more susceptible to negative effects of hypoxia during

Table 3 Result of GEE analysis for Lake Louise, $\mathrm{SpO}_{2}$, ACTN3 polymorphisms and glucose in the moments of 3 and $4 \mathrm{~h}$

\begin{tabular}{lll}
\hline Variable & $\beta(95 \% \mathrm{Cl})$ & $P$ \\
\hline $\mathrm{HR}$ & $-0.00(-0.04,0.02)$ & 0.63 \\
$\mathrm{SpO}_{2}$ & $-0.04(-0.08,-0.00)$ & $0.01^{*}$ \\
Lactate & $-0.19(-0.70,0.32)$ & 0.46 \\
$\mathrm{RR}$ & $2.08(1.02,3.13)$ & $<0.01^{*}$ \\
$\mathrm{RX}$ & $1.78(0.62,2.95)$ & $<0.01^{*}$ \\
$\mathrm{XX}$ & $0^{\mathrm{a}}$ & \\
glucose 3h & $-0.00(-0.02,0.02)$ & 0.96 \\
glucose 4h & $0.04(-0.00,0.08)$ & 0.08 \\
\hline
\end{tabular}

Note: The association between peripheral oxygen saturation $\left(\mathrm{SpO}_{2}\right), A C T N 3$ polymorphisms, glucose 3 and 4 Hours, and Lake Louise scores was verified by GEE analysis including all values of each volunteer in the five times (before, 1 $\mathrm{h}, 2 \mathrm{~h}, 3 \mathrm{~h}$ and $4 \mathrm{~h}$ ), totalizing 114 values for each variable. The values of genotypes are comparative among them, with $\mathrm{XX}$ being the reference value Cl Confidence Interval.

*Association between $\mathrm{SpO}_{2}$ and $\mathrm{RR}$ and $\mathrm{RX}$ genotypes with Lake Louise, $p<0.05$ acclimatization. This result, to a certain extent, corroborates previous findings that showed a higher prevalence of $\mathrm{X}$ allele in professional mountaineers when compared to normal individuals [40]; higher percentage of type I fibers in populations living in high altitudes such as Quechua of Peru [24] and the Sherpas and Tibetans [23] and in individuals with higher number of capillaries per muscle cross-sectional area [41], which could facilitate the supply of oxygen to the active muscles. Individuals expressing ACTN3 have at least one R allele, and homozygous (RR) individuals have a higher number of type IIx fibers than individuals with the XX genotype, with more type I fibers [42]. In addition, according to Hoppeler and Vogt [43], exposure to hypoxia causes a decrease of about $30 \%$ in mitochondrial density without a decrease in capillary density, which would lead to an increase in the supply of oxygen to mitochondria, favoring aerobic metabolism.

The association demonstrated in our study between the symptoms of AMS and ACTN3 genotypes is related to the decrease of $\mathrm{SpO}_{2}$, which is mainly responsible for the presence of AMS symptoms, with headache as the main symptom $[18,19]$. This data reinforces our hypothesis that the XX genotype of ACTN3 may have a faster acclimatization in situations of extreme altitude.

\section{Conclusion}

We conclude that there may be an association between the $\mathrm{R}$ allele of the ACTN3 R577X gene polymorphism and the susceptibility to develop the symptoms of AMS caused by a decreased $\mathrm{SpO}_{2}$.

\section{Limitations of the study}

Due to the fact that our study involves genetic variants, the number of analyzed volunteers may not be significant to show a definitive association. Furthermore, in a normobaric chamber, where adverse situations such as cold, wind and physical activity involved in the process of climbing at high altitudes are not present, the effects presented here may have been suppressed. Therefore, based on these restrictions, we suggest that new studies should be performed by other groups in hypobaric hypoxia in order to confirm the findings of this study.

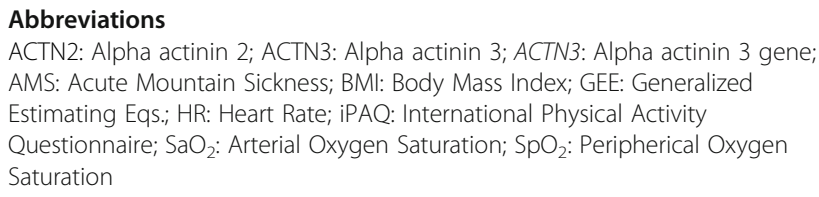

Acknowledgements

Not applicable

Authors' contribution

RMB collected and analyzed the data during the experiment, performed statistical analysis and wrote the manuscript. DCH also analyzed the data during the experiment. GHOL and JBP were responsible for the genotyping 
of volunteers and correction of the manuscript. All authors read and approved the final manuscript.

\section{Funding}

This paper is part of a master's degree dissertation, which was funded by the Coordenação de Aperfeiçoamento de Pessoal de Nível Superior - Brasil (CAPES), Associação Fundo de Incentivo à Pesquisa (AFIP) and Fundação de Amparo à Pesquisa do Estado de São Paulo (FAPESP, 2014/27198-8).

\section{Availability of data and materials}

The datasets used and/or analysed during the current study are available from the corresponding author on reasonable request.

\section{Ethics approval and consent to participate}

All volunteers signed a Free and Informed Consent Term (TCLE) and the study was approved by the Research Ethics Committee of the Federal University of São Paulo under number 2,001,055.

\section{Consent for publication}

Not applicable

\section{Competing interests}

The authors declare that they have no competing interests.

\section{Author details}

'Department of Psychobiology, UNIFESP, Botucatu Street, 862, First Floor, Vila Clementino, SP, ZIP, São Paulo 04023062, Brazil. ²Department of Biophysics, UNIFESP, São Paulo, Brazil.

\section{Received: 25 July 2019 Accepted: 10 October 2019}

Published online: 10 December 2019

\section{References}

1. Kenney WL, Wilmore JH, Costill DL. Exercício na Altitude. Fisiologia do Esporte e do Exercício. Barueri: Editora Manole; 2013.

2. Hodkinson PD. Acute Exposure to Altitude. J R Army Med Corps. 2011; 157(1):85-91.

3. Ni Q, Wan RQ, Jing YH, Dong XY, Zhang YC. Effect of Acute and Chronic Exposure to High Altitude on the Aerobic and Anaerobic Metabolism in Rats. Anal Cell Pathol. 2015. ID 159549

4. Rahn H, Otis AB. Man's respiratory response during and after acclimatization to high altitude. Am J Phys. 1949;157(3):445-62.

5. Bärtsch P, Swenson ER. Acute high-altitude illness. N Engl J Med. 2013 368(24):2294-302

6. Lipsitz LA, Hashimoto F, Lubowsky LP, Mietus J, Moody GB, Appenzeller O, Goldberger AL. Heart rate and respiratory rhythm dynamics on ascent to high altitude. Br Heart J. 1995;74(4):390-6.

7. Brooks GA, Butterfield GE, Wolfe RR, Groves BM, Mazzeo RS, Sutton JR Wolfel EE, Reeves JT. Increased dependence on blood glucose after acclimatization to 4,300 m. J Appl Physiol. 1991;70(2):919-27.

8. Brooks GA, Wolfel EE, Groves BM, Bender PR, Butterfield GE, Cymerman A, Mazzeo RS, Sutton JR, Wolfe RR, Reeves JT. Muscle accounts for glucose disposal but not blood lactate appearance during exercise after acclimatization to 4,300 m. J Appl Physiol. 1992;72(6):2435-45

9. Ge RL, Simonson TS, Gordeuk V, Prchal JT, McClain DA. Metabolic aspects of high-altitude adaptation in Tibetans. Exp Physiol. 2015;100(11):1247-55.

10. West J. The physiologic basis of high-altitude diseases. Ann Intern Med. 2004;41(10):789-800

11. Weil JV. Ventilatory control at high altitude. In: Cherniack NS, Widdicome JG editors. Handbook of physiology. eds ed. Bethesda: American Physiologic Society; 1986. p. 703-27.

12. Heistad DD, Abboud FM, Dickinson W. Richards lecture: circulatory adjustments to hypoxia. Circulation. 1980;61(3):463-70.

13. Bärtsch P, Gibbs SR. Effect of altitude on the heart and the lungs. Circulation. 2007;116(19):2191-202.

14. West J. Health considerations for managing work at high altitude. In: STELLMAN JM, Encyclopaedia of occupational health and safety. Geneva: International Labour Organization; 1998

15. Shah NM, Windsor JS, Meijer H, Hillebrandt D, Are UK. Commercial expeditions complying with wilderness medical society guidelines on ascent rates to altitude? J Travel Med. 2011;18:214-6.
16. Vardy J, Vardy J, Judge K. Acute Mountain sickness and ascent rates in trekkers above $2500 \mathrm{~m}$ in the Nepali Himalaya. Aviat Space Environ Med. 2006;77(7):742-4.

17. Carod-Artal FJ. High-altitude headache and acute mountain sickness. Neurologia. 2014;29(9):533-40.

18. Burtscher M, Mairer K, Wille M, Broessner G. Risk factors for high-altitude headache in mountaineers. Cephalalgia. 2011;31(6):706-11.

19. Karinen HM, Peltonen JE, Kähönen M, Tikkanen HO. Prediction of Acute Mountain sickness by monitoring arterial oxygen saturation during ascent. High Alt Med Biol. 2010;11(4):325-32.

20. Hsu TY, Weng YM, Chiu YH, Li WC, Chen PY, Wang SH, Huang KF, Kao WF, Chiu TF, Chen JC. Rate of ascent and Acute Mountain sickness at high altitude. Clin J Sport Med. 2014;25(2):95-104.

21. Roach RC, Bärtsch P, Oelz O, Hackett P. Lake Louise AMS Scoring Consensus Committee: The Lake Louise acute mountain sickness scoring system. In: Hypoxia and Molecular Medicine. JR Sutton, C Houston, G Coates, eds. Queen City printers, Burlington, VT. 1993. pp. 272-274.

22. Maclnnis MJ, Koehle MS, Rupert JL. Evidence for a genetic basis for altitude illness: 2010 update. High Alt Med Biol. 2010;11(4):349-68.

23. Gilbert-Kawai ET, Milledge JS, Grocott MP, Martin DS. King of the mountains: Tibetan and Sherpa physiological adaptations for life at high altitude. Physiology (Bethesda). 2014;29(6):388-402.

24. Rosser BW, Hochachka PW. Metabolic capacity of muscle fibers from highaltitude natives. Eur J Appl Occup Physiol. 1993;67(6):513-7.

25. North K, Beggs AH. Deficiency of a skeletal muscle isoform of a-actinin (aactinin-3) in merosin-positive congenital muscular dystrophy. Neuromuscul Disord. 1996;6(4):229-35

26. North KN, Yang N, Wattanasirichaigoon D, Mills M, Easteal S, Beggs AH. A common nonsense mutation results in alpha-actinin-3 deficiency in the general population. Nat Genet. 1999:21(4):353-4.

27. Walsh PS, Metzger DA, Higushi R. Chelex 100 as a medium for simple extraction of DNA for PCR-based typing from forensic material. Biotechniques. 2013;54(3):134-9.

28. Desjardins P, Conklin D. NanoDrop microvolume quantitation of nucleic acids. J Vis Exp. 2010;22(45):2565.

29. Schadock I, Schneider A, Silva ED, Buchweitz MR, Correa MN, Pesquero JB, Paredes-Gamero EJ, Araujo RC, Barros CC. Simple method to genotype the ACTN3 r577x polymorphism. Genet Test Mel Biomarkers. 2015;19(5):253-7

30. Roach RC, Hackett PH, Oelz O, Bärtsch P, Lucks AM, Maclnnis MJ, Bailie JK The Lake Louise AMS Score Consensus Committee. The. Lake Louise Acute Mountain sickness score. High Alt Med Biol 2018. 2018;19(1):4-6.

31. Iyriboz Y, Powers S, Morrow J, Ayers D, Landry G. Accuracy of pulse oximeters in estimating heart rate at rest and during exercise. $\mathrm{Br} J$ Sports Med. 1991;25(3):162-4

32. Baldari C, Bonavolontà V, Emerenziani GP, Gallotta MC, Silva AJ. Guidetti L accuracy, reliability, linearity of Accutrend and lactate pro versus EBIO plus analyzer. Eur J Appl Physiol. 2009;107(1):105-11.

33. Dunn PK. Occurrence and quantity of precipitation can be modelled simultaneously. Int J Climatol. 2004;24:1231-9.

34. Swan T. Generalized Estimating Equations When the Response Variable Has a Tweedie Distribution: An Application for Multi-Site Rainfall Modelling. Honours thesis. University of Southern Queensland, Department of Mathematics and Computing; 2006.

35. SanMartin R, Brito J, Siques P, Léon-Velarde F. Obesity as a conditioning factor for high-altitude diseases. Obes Facts. 2017;10:363-72.

36. Rupp T, Jubeau M, Millet GY, Perrey S, Esteve F, Wuyan B, Levy P, Verges S. The effect of hypoxemia and exercise on acute mountain sickness symptoms. J Appl Physiol. 2013;114:180-5.

37. Kelly KR, Williamson DL, Fearly CE, Kriz DA, Krishnan RK, Huang H, Ahn J, Loomis JL, Kirwan JP. Acute altitude-illness hypoxia suppresses plasma glucose and leptin in healthy humans. Metabolism. 2010;59:200-5.

38. Tomar A, Malhotra S, Sarkar S. Polymorphism profiling of nine high altitude relevant candidate gene loci in acclimatized sojourners and adapted natives. BMC Genet. 2015;16:112.

39. Maclnnis MJ, Koehle MS. Evidence for ans against genetic predispositions to acute and chronic altitude illness. High Alt Med Biol. 2016;17(4):281-93.

40. Djarova T, Bardarev D, Boyanov D, Kaneva R, Atanasov P. Performance enhancing genetic variants, oxygen uptake, heart rate, blood pressure and body mass index of elite high altitude mountaineers. Acta Physiol Hung. 2013;100(3):289-301. 
41. Kayser B, Hoppeler H, Desplanches D, Marconi C, Broers B, Cerretelli P. Muscle ultrastructure and biochemistry of lowland Tibetans. J Appl Physiol. 1996;81(1):419-25.

42. Vincent B, De Bock K, Ramaekers M, den Eede EV, Van Leemputte M, Hespel $P$, Thomis MA. ACTN3 (R577X) genotype is associated with fiber type distribution. Physiol Genomics. 2007;32:58-63.

43. Hoppeler H, Vogt M. Muscle tissue adaptations to hypoxia. J Exp Biol. 2001; 204(Pt 18):3133-9 Review.

\section{Publisher's Note}

Springer Nature remains neutral with regard to jurisdictional claims in published maps and institutional affiliations.

Ready to submit your research? Choose BMC and benefit from:

- fast, convenient online submission

- thorough peer review by experienced researchers in your field

- rapid publication on acceptance

- support for research data, including large and complex data types

- gold Open Access which fosters wider collaboration and increased citations

- maximum visibility for your research: over $100 \mathrm{M}$ website views per year

At BMC, research is always in progress.

Learn more biomedcentral.com/submissions 